\title{
Clubfoot treatment in China before and after the advent of the Ponseti technique: a historical narrative review
}

\author{
Jingchun $\mathrm{Li}^{1} \wedge$, Yiqiang $\mathrm{Li}^{1 \wedge}$, Hongwen $\mathrm{Xu}^{1} \wedge$, Federico Canavese ${ }^{2,3} \wedge$ \\ ${ }^{1}$ Department of Paediatric Orthopaedics, Guangzhou Women and Children's Medical Centre, Guangzhou Medical University, Guangzhou, China; \\ ${ }^{2}$ Lille University Center, Jeanne de Flandre Hospital, Department of Pediatric Orthopedic Surgery, Lille, France; ${ }^{3}$ Nord-de-France University, \\ Faculty of Medicine Henri Warembourg, Lille, France \\ Contributions: (I) Conception and design: J Li, F Canavese; (II) Administrative support: All authors; (III) Provision of study materials or patients: J Li, \\ Y Li, H Xu; (IV) Collection and assembly of data: All authors; (V) Data analysis and interpretation: All authors; (VI) Manuscript writing: All authors; \\ (VII) Final approval of manuscript: All authors. \\ Correspondence to: Dr. Hongwen Xu, MD, PhD. Department of Paediatric Orthopaedics, Guangzhou Women and Children's Medical Centre, \\ Guangzhou Medical University, Guangzhou, Guangdong, China. Email: xuhongwen@gwcmc.org; Prof. Federico Canavese, MD, PhD. \\ Lille University Center, Jeanne de Flandre Hospital, Department of Pediatric Orthopedic Surgery, Rue Eugène Avinée, 59000 Lille, France. \\ Email: canavese_federico@yahoo.fr.
}

\begin{abstract}
Congenital clubfoot (CF) was first described by Hippocrates in approximately 400 B.C. In ancient China, manipulations were widely used to correct CF, but the outcomes were frequently unsatisfactory with residual deformity even if corrective devices were used. The advent of aseptic surgery and anesthesia has favored the development of different surgical procedures to manage children with CF. Surgical treatment became extremely popular in China during the years 1960-1990 due to the good clinical foot appearance post-surgery. However, the poor mid- to long-term results of surgical treatment facilitated the return of conservative treatment, i.e., the Ponseti technique. Over the past decade, the Ponseti technique has become very popular in China. The Ponseti technique is essentially conservative and it is based on a good understanding of CF pathophysiology. Casts are changed once a week and Achilles tenotomy is performed if equinus persists at the end of treatment. Although highly successful on the short to mid-term, the Ponseti technique is not able to completely eradicate surgery, and recurrence is still possible. As the etiology of $\mathrm{CF}$ is still unclear, the first mission for doctors and researchers all over the world is to truly understand the pathogenesis of the deformity. Even though genetics seems to play an important role, successful gene therapy is still a distant goal. This narrative review aims to investigate the history of CF treatment in China, to describe its tortuous process and to potentially inspire new ideas to create new effective methods of treatment.
\end{abstract}

Keywords: Clubfoot; China; surgery; treatment; Ponseti

Submitted Dec 17, 2020. Accepted for publication May 14, 2021.

doi: $10.21037 /$ atm-20-8042

View this article at: http://dx.doi.org/10.21037/atm-20-8042

$\wedge$ ORCID: Jingchun Li, 0000-0001-7195-0335; Yiqiang Li, 0000-0002-0837-4942; Hongwen Xu, 0000-0003-3157-2514; Federico Canavese, 0000-0002-6114-5372. 


\section{Introduction}

Clubfoot deformity (talipes equinovarus, supinatus and adductus) was first described by Hippocrates more than 2000 years ago (about 400 years before Jesus Christ) (1). In China, traditional Chinese medicine (TCM) considers the clubfoot deformity a teratological defect (teratology: the branch of anatomy studying abnormalities of physiological development). In ancient times, TCM professionals mainly used Chinese herbal medicine to treat diseases, so they could not develop any specific technique to manage children with congenital clubfoot (CF). In China, manipulations were usually performed to correct the deformity as the Western practitioners did in ancient times (2). In particular, given that $\mathrm{CF}$ was not considered to be a severe illness, as it did not endanger the lives of the patients, nor affect life expectancy (like other congenital malformations such as polydactyly, for example), the Chinese government and TCM professionals did not pay much attention to patients with CF. For this reason, historical data on patients with $\mathrm{CF}$ are extremely scarce.

The development of western medicine has contributed to popularize the surgical treatment of CF in China, and several scientific articles about different surgical procedures have been published. However, the principles of CF treatment among Chinese practitioners started gradually to change and switch toward conservative treatment due to the poor functional outcome of operated feet (up to $30 \%$ of poor mid- to long-term results). The Ponseti method has become the most popular treatment method of CF worldwide because is inexpensive, reproducible and with good long term outcomes. Cast are changed once a week and Achille's tenotomy is performed once a week if dorsiflexion is lacking at the end of treatment. Although, more than $90 \%$ of clubfoot can be initially corrected, the relapse rate is as high as $50 \%$, according to the literature. In case of recurrence, transfer of the anterior tibialis tendon (TATT) is usually performed. Ponseti method does not completely eliminate the need for surgery.

Chinese medicine represents a large portion of global medicine, and, over the centuries, has developed different treatment concepts compared to western world. Reviewing the history and learning from difference among different treatment philosophies can improve the understanding of the CF pathology.

This narrative review aims to investigate the history of CF treatment in China, to describe its tortuous process and to inspire new ideas to create new effective methods of treatment. We present the following article in accordance with the Narrative Review reporting checklist (available at http://dx.doi.org/10.21037/atm-20-8042).

\section{Search strategy}

We extensively search on commonly used biomedical databases, including PubMed, Embase, MedLine (OVID), Web of Science, Cochrane Library, and Sinomed from the inception of relevant database to December 2020. Moreover, additional databases such as The Taiwan Academic Literature Database (http://www.airitilibrary.cn/) and The Hong Kong University Theses Collection (HKUTO; http://hub.hku.hk/) were screened. We combined subject words and keywords using Boolean operators to search with no limitations on year of publication and language. All articles were reviewed by the two authors of this narrative review (JL and YL). All articles were level IV case series and expert opinion and, hence no systematic assessment of study quality was performed.

\section{The tortuous history of clubfoot treatment in China}

In ancient times of China, people used to choose manipulations method to correct the clubfoot deformity as the Western practitioners did. The outcome of treatment in that time was usually not good.

Missionaries introduced Western medicine to China around the $16^{\text {th }}$ century. Before that time, children with CF were treated by TCM professionals, with not ideal results. However, at that time, ophthalmology was the only medical specialty involved in the care of Chinese patients; foot and lower extremity deformities were rarely treated by western method. During the $18^{\text {th }}$ century, some Chinese practitioners had the opportunity to receive their education in Western universities and hospitals, and they acquired very good knowledge of Western medicine. However, when they returned to China, they could treat almost exclusively ophthalmological disorders because there was a great deal of reservation toward Western medicine. It was only during the $19^{\text {th }}$ century that the Chinese government realized that Western technology and knowledge could contribute to the advancement of Chinese society and medicine. As a result, the Chinese government decided to send students abroad to learn about Western technologies, including medicine. It was only after World War II that Western medicine was officially recognized in China, and disorders such as CF 


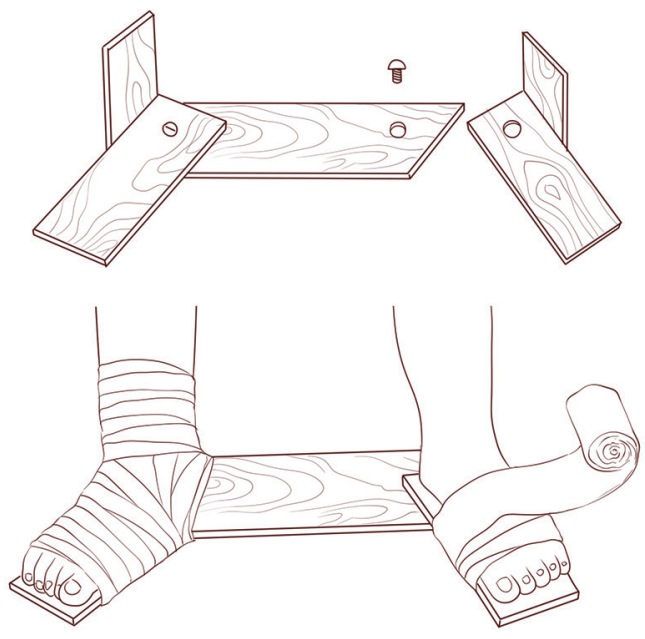

Figure 1 Self-designed brace (Shi JH: Massage therapy for congenital hand and foot deformity in children. Central Plains Medical fournal. 1985:30-31).

could be treated accordingly.

Moreover, the advent of anesthesia (at the end of the $19^{\text {th }}$-beginning of the $20^{\text {th }}$ century) and the introduction of aseptic surgery allowed Western surgeons to develop different surgical techniques that were then introduced gradually to China.

Lambrinudi arthrodesis for severe equinovarus deformities in adults and in children was probably one of the first surgical procedures that was introduced to Chinese practitioners between the 1960s and 1980s. During this period, all children with CF aged less than two years of age were treated by progressive manual reduction and plaster immobilization; however, for some mild cases, soft bands could be used instead of plaster. On the other hand, patients between 2 and 10 years of age, were managed by soft tissue procedures while bony surgery (osteotomies) was reserved for patients older than 10 years of age (3). It is important to note that at that time, most Chinese practitioners preferred surgery to treat patients with CF including infants $(4,5)$; muscle balance surgery was also used to treat children with CF during this same time period (6-8). Because of the good clinical foot appearance post-surgery, surgical treatment of CF became extremely popular in China.

Kite's method was used to treat CF as early as 1965 , and it was introduced in China at that time. Zhou et al. used the Kite's method to treat children with CF; in particular, they manipulated the foot 5 to 10 minutes prior to casting. The long leg cast was changed every 3 to 4 weeks over a period of 3-9 months, depending on the severity of the deformity.
In particular, at 11 years follow-up, the outcome was good in 28 out of 35 feet (80\%) (9).

During the 1960s, manipulations were mostly performed in the TCM hospitals, where the practitioners used soft bands, similar to those used in the French Functional Physical Therapy method, to immobilize the foot in the position obtained with gradual and progressive manipulations (10) (Figure 1); results were acceptable in most patients that were able to ambulate without major pain or discomfort.

During the 1980 s, early diagnosis and treatment became the gold standard of CF treatment. Conservative treatment aimed for early correction of all components of the deformity even though some feet would still require surgical intervention later to achieve a painless, plantigrade foot. Surgical interventions ranged from a percutaneous heel cord lengthening to a wide release of posterior, medial and lateral structures, with or without TATT. At that time, conservative treatment was recommended to treat infants from birth to 6 months of age; in particular, infants aged less than 3 months were usually managed by manipulations alone, while those over 3 months of age were treated by manipulations and cast immobilization, even though some practitioners preferred to use elastic bandages. To maintain the reduction, some practitioners used a splint or selfdesigned sheaths instead of a plaster cast $(11,12)$ (Figure 2). Patients aged between 6 months and 2 years were treated by conservative means; however, if the deformity could not be corrected, the TATT and/or the Achilles' tendon lengthening was recommended. At that time, extensive soft tissue procedures (posterior and medial release) and arthrodesis were reserved for patients older than 2 years of age (13). On the other hand, patients older than 10 years of age with severe CF deformity were managed by the Lambrinudi arthrodesis; in order to decrease tension on the skin following deformity correction, the use of a dorsal fascial flap was added to the procedure (14); in particular, Zhang et al. reported good outcome in 20 severe CF treated with the procedure, and did not report any case of skin flap necrosis nor wound infection. Despite the encouraging results, no further studies were published on the subject at a later time. At that period, surgical treatment (early or late) was still the preferred option to treat CF (15-21).

Nevertheless, during the 1990s, the high rates of complications associated with extensive surgery and the poor outcomes of conservative treatment prompted doctors to turn to other treatment options $(22,23)$. In particular, split TATT was used to avoid the excessive hind foot 

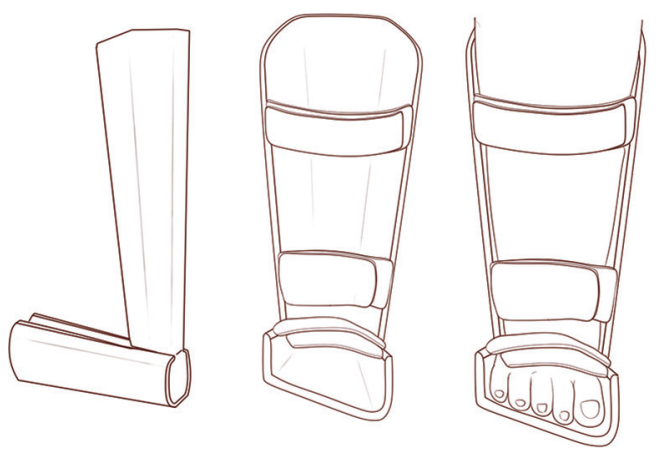

Figure 2 Metal brace (Ling JB: Zheng's manipulation massage combined with aluminum alloy stent to treat congenital clubfoot in children. Fournal of Chengdu Sport University. 1994:34-36).

valgus secondary to surgical release (24). Alternatively, the Bridle procedure (posterior tibial tendon, long peroneal tendon and anterior tibial tendon are sutured together) was performed to avoid excessive hind foot valgus (25). All the patients had very good results after the operation according to the report, but the total number of cases was low (13 patients and 21 feet), and the follow up was short (6-18 months). Similarly, the transposition of the flexor longus muscle to the peroneal longus muscle in order to reinforce the strength of the peroneal muscle was also used in patients with CF (26). In particular, Gao et al. reported good outcome in 32 patients (34 feet) treated with such procedure. However, the classic surgical procedures, such as the posterior and medial release, and the TATT, were also used by Chinese surgeons (23,27-31).

Extensive posterior and medial release surgery was largely performed throughout China during that time $(32,33)$. In particular, McKay's procedure was widely used in several Chinese institutions (33-38), where orthopedic and pediatric surgeons used this method to treat infants of approximately 3 months of age (39-41). According to these reports, good correction could be achieved in about $95 \%$ of cases; none of the patients developed serious adverse event though the mean follow-up was short (1 year). On the other hand, Ilizarov's external fixation technique was used to treat some older patients (42-44). However, due to the long period of hospitalization and the high costs, the technique was not widely used. At the same time, Kite's method and other conservative treatment were still the preferred treatment option by some other doctors $(28,45-47)$. Before the year 2000, the Ponseti method began to be used in a few Chinese institutions although none reported their results (48). In 1994, George Simon's book, "The clubfoot.
The present and a view of the future" (49), granted a limited place to the orthopedic treatment of CF, and Ponseti's technique is not mentioned at all. That work surfaced in the mid-1990s following the publication of Cooper and Dietz's article, "Treatment of idiopathic clubfoot. A thirtyyear follow-up note" in 1995 (50), and Ponseti's book, "Congenital Clubfoot, Fundamentals of treatment" in 1996 (51). At the same time, many authors reported poor results with extensive surgery according to McKay and Simons (52-57). In this context, reported rates of up to $30 \%$ of poor mid- to long-term results facilitated the coming back of conservative management of CF.

Therefore, during the 2000s, the principles of CF treatment among Chinese practitioners started gradually to change and switch toward conservative treatment. Although surgical treatment was still used, increasingly more practitioners started to apply conservative protocols as initial CF treatment. Subsequently, conservative treatment has become the first-line treatment for CF deformity correction, and two main methods of treatment have been developed: the Ponseti technique (Iowa City, USA) and the French functional physiotherapy method (Paris and Montpellier, France). Serial casting and manipulations and gentle manipulations by a skilled physiotherapist are at the core of the Ponseti technique (48,58-63) and the French functional physiotherapy method (64), respectively.

Although these two techniques revolve around different clinical approaches, both protocols have shown good efficacy, reliability, and lasting outcomes and are reported to perform comparably with initial correction rates of up to $90 \%$. Both protocols aim to achieve a painfree supple plantigrade foot with as little surgery as practicably possible, as long-term studies on outcomes of surgical releases have reported high rates of painful and stiff feet with poor functional outcomes. However, these protocols are not able to eliminate the need for surgery completely (65). Surgical treatment is only needed when the orthopedic treatment is no longer effective and/or when the foot shows no additional improvement. Minimally invasive surgical procedures such as Carroll's technique were introduced in China $(66,67)$. In particular, the selective release of the tendon of the abductor hallucis tendon and of the plantar fascia reduced the total time of cast treatment. However, many practitioners felt it was not worth doing the surgery because such technique could only decrease the cast by $1-2$ weeks.

During this period, the majority of Chinese practitioners switched to conservative treatment, while very few are still 
using surgery even though surgery is mostly reserved for recurrent and resistant cases.

Since the year 2010, treatment of CF in China has matched international guidelines, and conservative treatment has also become the gold standard in older children (68); very few hospital are still performing surgical treatment as the initial CF treatment. Over the years, the Ponseti technique has become very popular in China. The Ponseti technique is essentially conservative, and it is based on serial castings that are changed on a weekly basis.

Correction starts in the horizontal plane. The first couple casts of are applied with the forefoot supinated, to bring it into alignment with the hind foot. Ponseti pointed out not to correct the supination by lowering the first metatarsal bone, which results in a worsening of the cavus. Subsequent casts are made with the forefoot progressively abducted with simultaneous counter pressure over the head of talus. Prior to the last cast, the degree of dorsiflexion is assessed, and if dorsiflexion is limited, a percutaneous Achilles tenotomy is required. Following full correction, the feet are placed in a Denis-Browne bar or in a Foot Abduction Orthosis (FAO), which is used for 23 hours a day in the initial 4 to 6 months and then subsequently at nighttime for three to five years.

Indisputably, the Ponseti method is effective although it does not completely eliminate the need for surgery. It is obvious that the more severe the CF deformity is, the higher the risk of surgery is. Following the return of conservative treatment, a new surgery-limited, thrifty, and kind-has born: the surgery "à la carte", which joins the French philosophy. CF has multiple clinical facets and regardless of the method of treatment, the goals are the same, to achieve a plantigrade, painless and supple foot, to diminish the frequency and extent of surgery as much as possible and to decrease the risk of relapse.

\section{TCM and clubfoot}

TCM has played an important role in Chinese medical history as it has been successfully involved in the treatment of several disorders. Although TCM usually pays attention to the whole body rather than to a single organ (i.e., the foot), massage therapy has been used to treat CF deformity (28,69-72). However, because of the limited understanding of the underlying pathogenic mechanisms of CF deformity, the outcome of TCM massage therapy is not fully positive, especially in patients with severe and stiff deformity. Following the introduction of the Ponseti technique, massage therapy per TCM guidelines has been used to keep the foot supple and the ankle mobile during brace treatment $(72,73)$. Acupuncture and moxibustion anesthesia have also been used to assist surgery (74). TCM is different from Western medicine as it aims to support the human body to self-repair itself. Currently, several Chinese practitioners are treating patients with CF by integrating TCM principles with Western medicine concepts (75-77). Unfortunately, the studies reporting on these treatment protocols do not have the methodological standards required by modern science, and the results are not known outside China. Future studies that are methodologically sound are needed to prove the efficacy of combining TCM with Western treatment protocols.

\section{Discussion}

The Ponseti method has revolutionized the approach to treating CF. The Ponseti method is based on conservative means, i.e., serial casting and manipulations, however, the use of manipulations to correct the deformity had been introduced by Hippocrates more than 2000 years ago (2). One of the reasons why the Ponseti technique has gained popularity all over the world and has achieved excellent correction rates is that Dr. Ponseti understood the pathoanatomy of the disease (thanks to his anatomical dissections of fetuses) and, subsequently, on the basis of his observations set up his treatment protocol (78).

The etiology of CF is still unknown although several theories have been formulated to explain it. In particular, CF can be caused by vascular deficiencies, position in utero, abnormal congenital muscle insertions as well as genetic factors. The future treatment of CF will involve understanding of the pathogenetic mechanisms of the CF deformity.

Although the Ponseti technique is performed all around the world, it has not been adopted everywhere; in particular, some institutions do manage patients with CF with manipulations and physiotherapy (French method). The same trend is observed in China, where other techniques for CF correction are used, for example, the so-called polyaxial fixation metal braces have been successfully used to treat CF in China (79) (Figure 3A,B). Presently, the general principle of early diagnosis and treatment is widely accepted, however, some treatment modalities may vary. Similarly, although the principles of the Ponseti technique are accepted, the type of cast material used may vary. In particular, some surgeons use the traditional plaster as suggested by Dr. Ponseti while others use semirigid or rigid 

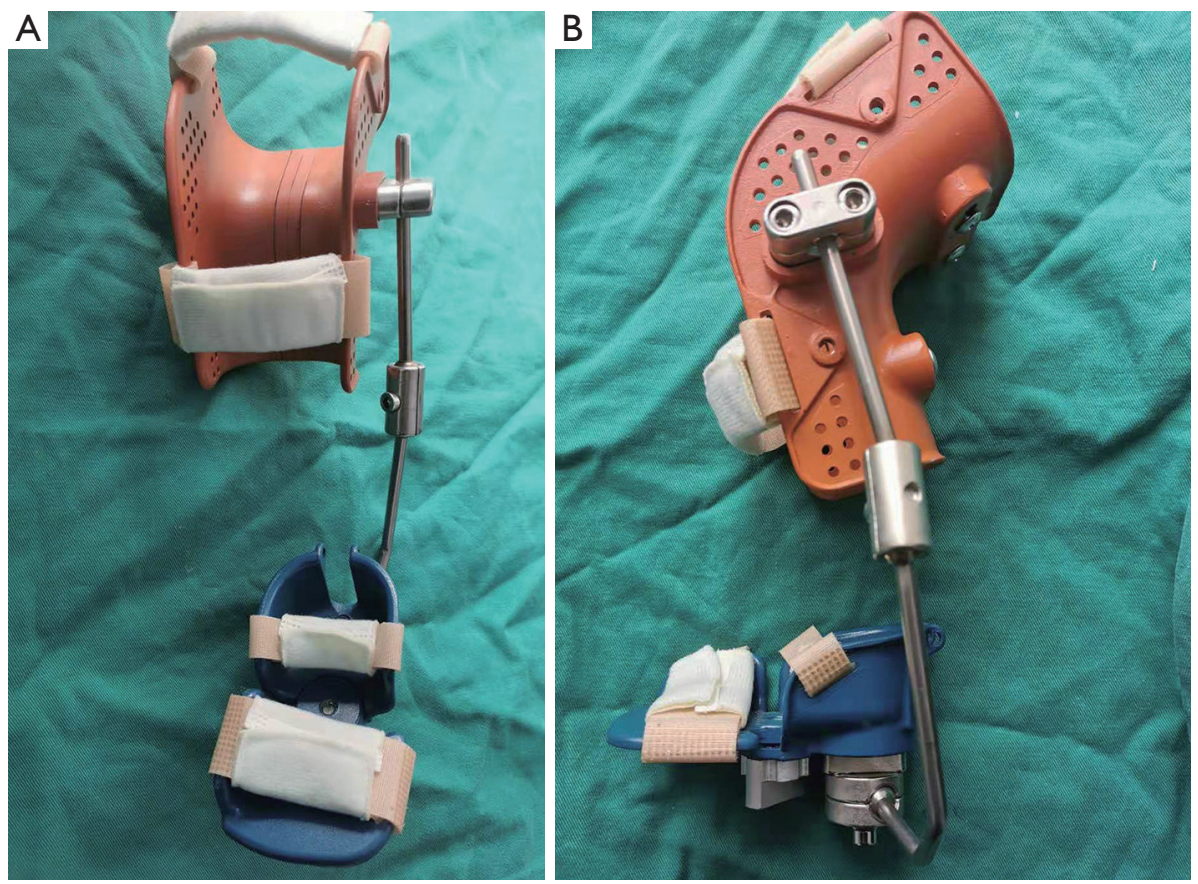

Figure 3 Polyaxial fixation brace for treating congenital clubfoot. (A) Frontal view; (B) lateral view (Su Y, Xie Y, Kang X, Nan G: A polyaxial fixation brace for the treatment of idiopathic congenital talipes equinovarus in newborns. 7 Orthop Surg Res. 2019, 14:211).

fiberglass casts. Hui et al. found that there was no significant difference in the number of casts required for correction of clubfoot between the traditional plaster and semirigid fiberglass cast (80).

According to Ponseti, about half of the relapses have a tendency to occur between 10 months and five years of age, regardless of the degree of correction obtained with conservative treatment. The primary reason for relapses is the inability of families to maintain the correction initially achieved with conservative treatment. Therefore, substantial follow-up is necessary to evaluate the effect of treatment as deteriorations can be observed around and after two years of age $(81,82)$. For this reason, many Chinese institutions have developed specific sessions to explain to parents and caregivers the necessity of wearing braces (to improve the parents' compliance) in order to avoid recurrence of the deformity $(83,84)$; these session are also available online (85). The type of brace varies among different Chinese institutions; some centers prescribe Denis-Browne shoes and others the Ponseti-Mitchell or Dobbs shoes. Selecting the type of brace is mainly depend on the doctor's suggestion. For example, Ponseti-Mitchell shoes are generally selected because silicone is better tolerated than leather while Dobbs shoes allow the children to move more. However, it is important to note that in some situations, parents want to select the shoes for their children by themselves.

Currently, the treatment of CF in China is carried out as in Western countries, and the trend is to favor conservative treatment. The best method to treat CF must be simple, effective and inexpensive. The Ponseti method meets these criteria, and therefore, it has been accepted worldwide. However, the Ponseti technique cannot treat all CF deformities as the recurrence rate is not negligible. For this reason, a new treatment method based on the understanding of the pathogenetic factors of the disease is needed to improve the care of children with CF. For this reason, basic research studies on the etiology of CF are rapidly expanding in China (86-92) and around the world (93-95). Although there is still a long way to go, only continuous exchanges between caregivers and researchers as well as international and interregional cooperation will guide the medical community towards the best possible care for children with CF.

\section{Acknowledgments}

We thank Dr. Xiaopan Chang for drawing the pictures. We 
also thank Dr. Dong Liu for his help with the literature search. We also thank Prof. Guoxin Nan for providing Figure 3.

Funding: This study was supported (or partially supported) by the fund from Guangzhou Institute of Pediatrics/ Guangzhou Women and Children's Medical Center (No.: YIP-2016-008).

\section{Footnote}

Provenance and Peer Review: This article was commissioned by the editorial office, Annals of Translational Medicine for the series "Clubfoot". The article has undergone external peer review.

Reporting Checklist: The authors have completed the Narrative Review reporting checklist. Available at http:// dx.doi.org/10.21037/atm-20-8042

Conflicts of Interest: All authors have completed the ICMJE uniform disclosure form (available at http://dx.doi. org/10.21037/atm-20-8042). The series "Clubfoot" was commissioned by the editorial office without any funding or sponsorship. Federico Canavese served as the unpaid Guest Editor of the series and serves as an unpaid editorial board member of Annals of Translational Medicine from Nov 2020 to Oct 2022. The authors have no other conflicts of interest to declare.

Ethical Statement: The authors are accountable for all aspects of the work in ensuring that questions related to the accuracy or integrity of any part of the work are appropriately investigated and resolved.

Open Access Statement: This is an Open Access article distributed in accordance with the Creative Commons Attribution-NonCommercial-NoDerivs 4.0 International License (CC BY-NC-ND 4.0), which permits the noncommercial replication and distribution of the article with the strict proviso that no changes or edits are made and the original work is properly cited (including links to both the formal publication through the relevant DOI and the license). See: https://creativecommons.org/licenses/by-nc-nd/4.0/.

\section{References}

1. Vallejo JR, Mesa M, Cobos-Bueno JM. Francisco Arceo de Fregenal and the treatment of clubfoot up to the sixteenth century. Acta Med Hist Adriat 2018;16:19-48.
2. Hernigou P. History of clubfoot treatment; part III (twentieth century): back to the future. Int Orthop 2017;41:2407-14.

3. Yu B. Early treatment of clubfoot deformity (report of 43 cases). Ningxia Medicine Communications 1982;24:59-60.

4. Lu YP, Wang CL, Huang YT, et al. Treatment of congenital clubfoot by early operation. Orthopedics 1988;11:1093-101.

5. Wang RK. Surgical treatment of congenital clubfoot in children. Heilongjiang Medicine and Pharmacy 1980;3:57-9.

6. Huang YT, Lei W, Zhao L, et al. The treatment of congenital club foot by operation to correct deformity and achieve dynamic muscle balance. J Bone Joint Surg Br 1999;81:858-62.

7. Jiang QL. Clinical application of congenital CLUBFOOT muscle balance in early childhood. Journal of Guangxi Medical College 1990;7:77-8+80.

8. Chen CS, Liu PT, Wen LK. Early Surgical Treatment of 300 Cases of Congenital Clubfoot. Shandong Medical Journal 1991;31:21.

9. Zhou YD, Ji SJ, Ji SR, et al. Long-term effect of plaster on congenital clubfoot. Journal of China Medical University 1984;13:51-4.

10. Shi JH. Massage therapy for congenital hand and foot deformity in children. Central Plains Medical Journal 1985;31:30-1.

11. Chen KG. Treatment of congenital clubfoot with massage and orthosis. Chinese Manipulation \& QiGong Therapy 1993;53:25-7.

12. Ling JB. Zheng's manipulation massage combined with aluminum alloy stent to treat congenital clubfoot in children. Journal of Chengdu Sport University 1994;20:34-6.

13. Song NL. Congenital clubfoot. The Journal of Traditional Chinese Orthopedics and Traumatology 1987;3:71-5.

14. Zhang CS, pang BS, Zhang GM, et al. Retrofit of dorsal fascia flap for correction of severe clubfoot in children. Journal of Nongken Medicine 1988;10:242-3.

15. Song JX, Zhou JZ, Kang Z, et al. A report of 78 cases of congenital clubfoot treated by surgery. Harbin Medical Journal 1994;14:3-5.

16. Tian BC, Cao L, Zhang SM, et al. Treatment of congenital clubfoot with posterior release. Chinese Journal of Orthopaedics 1995;15:126-7.

17. Wang YJ, Mi JX, Hou XM, et al. Treatment of 48 cases of congenital clubfoot by soft tissue release and anterior tibial muscle displacement. Acta Academiae Medicinae Weifang 
$1995 ; 17: 42-3$.

18. Xu QZ, Tan WB, Zhang DY, et al. Treatment of congenital clubfoot in children with posterior medial release and tibialis anterior transfer. Medical Journal of National Defending Forces in Northwest China 1995;16:84-6.

19. Xu QZ, Jia LS, Xu KH, et al. Turco release of anterior tibialis muscle in children with congenital clubfoot. Chinese Journal of Pediatric Surgery 1995;16:36-8+63-4.

20. Huang YT, X. LJ, Lei W, et al. Long-term effect of early muscle balance surgery on congenital clubfoot. Chinese Journal of Pediatric Surgery 1996;17:66-9.

21. Qi Y, Guo BZ, Wang MS. Treatment of tendon shortness in treating congenital clubfoot by using posterior tibial muscle transfer. Journal of Medical Science Yanbian University 1996;19:233-4.

22. Hang YT, Xu LS, Lei W, et al. Causes of Unsuceessful Sugrieal Treatment for Congenital Clubfoot in Children. Chinese Journal of Pediatric Surgery 1997;18:301-3.

23. Yang GX, Cai HQ, Du Q, et al. Experience of the treatment of severe congenital clubfoot with complete release of subtalar. Chinese Journal of Pediatric Surgery 1998;19:3-5.

24. Zhang ZG. Treatment of severe congenital clubfoot by partial anterior tibial muscle displacement. Chinese Journal of Coal Industry Medicine 2000;3:50.

25. Zhang JJ. Treatment of congenital equinovarus in children by using soft tissue release and Bridle's procedure. Journal of Clinical Orthopaedics 2000;3:54-5.

26. Gao SL, Bai DL, Tang WC. Strengthening fibular muscle for children's congenital pes equinovarus. Journal of Shanxi Medical University 2001;32:185-6.

27. Wang YL. Clinical Analysis of Early Treatment of Congenital clubfoot. Journal of Lanzhou University(Medical Sciences) 1998;24:3-5.

28. Zhang YP, Liu YF, Lin ZY. Manual correction of plaster fixation in the treatment of congenital clubfoot in children. Fujian Journal of Traditional Chinese Medicine 1998;29:3-5.

29. Li SM, Lin GS. Prolonged Achilles tendon and anterior tibial transfer for congenital clubfoot. Orthopedic Journal of China 1999;6:3-5.

30. Lu LF. Etiology, pathology and treatment of congenital clubfoot. Guangxi Medical Journal 1999;21:3-5.

31. Sun J, Yuan Y. The treatment of recurrent congenital equinovarus by using muscle balance. The Journal of Practical Medicine 1999;15:3-5.

32. Tian XH, Jiang H. Treatment of severe congenital clubfoot with extensive medial and posterior soft tissue release. Clinical Medicine of China 2000;16:40-1.

33. Qi YB. Mckay treatment of congenital clubfoot. Zhejiang Clinical Medical Journal 2000;2:769.

34. Li M, Liu Z, Zhang D. McKay operation in the correction of rigid clubfoot. Zhongguo Xiu Fu Chong Jian Wai Ke Za Zhi 1998;12:288-90.

35. Wu XL, Reng DS, Wang BL, et al. Application of modified Mckay in the treatment of congenital clubfoot. Journal of Clinical Pediatric Surgery 2005;4:166-8.

36. Qin JQ, Li M, Zhang DW, et al. Mckay and modified Mekay procedure treatment for equinovarus deformity of arthrogryposis multiplex congenita. Chongqing Medicine 2007;36:1469-70.

37. Lai DM. Combined operation of modified Mckay for congenital clubfoot. Jiangxi Medical Journal 2008;43:995-6.

38. Lv GR, Li GS, Zhang HY. Effect of Mckay Procedure in the Treatment of Patients with Congenital Talipes Equinovarns. Chinese Journal of Clinical Medicine 2011;18:525-6.

39. Chen ZJ, Tian JJ. Effect of surgical treatment on congenital clubfoot in infants. Journal of Xuzhou Medical University 1997; 17:85-6.

40. Li FJ, Zhang YY, Deng YF, et al. Early surgical treatment of congenital clubfoot in infants. Hebei Medicine 1998;3:3-5.

41. Tian JJ, Lu EH, Chen ZJ. Obervation on surgical treatment of congenital clubfoot in infants. Journal of Practical Orthopaedics 1998;4:3-5.

42. Fan YH, Huang LJ, Tang K. Complications of Ilizarov Technique in the Treatment for Lower Extremital Deformity. Chinese Journal of Pediatric Surgery 1998;19:3-5.

43. Xia RX, Lou Y, Tand K. Operative treatment of congenital clubfoot. Journal of Clinical Orthopaedics 1999;2:3-5.

44. Huang LJ, Fan YH, Xia RX, et al. Treatment of severe and recurrent congenital clubfoot with external fixator (report of 23 cases). Jiangsu Medical Journal 2000;26:138.

45. Shi YC. Simple Pediatric Ankle Orthopedic Footwear. Chinese Journal of Pediatric Surgery 1999;2:3-5.

46. Sun CZ, Wang GZ, Zhang XK. Treatment of congenital clubfoot in children with posterior release and anterior tibial muscle transfer (report of 18 cases). Journal of Jiangsu Clinical Medicine 2001;5:402-3.

47. Tao PX, Deng ZS, Wang DH, et al. Treatment of congenital clubfoot with low temperature hot plastic splint. China Journal of Modern Medicine 2001;8:99-100.

48. Yang JP, Li DD, Gong RY, et al. Ponseti procedure in early 
non-operative treatment for congenital talipes equinovarus. Chinese Journal of Pediatric Surgery 2003;24:13-5.

49. Simons GW. The clubfoot. The present and a view of the future. First ed. New York: Springer-Verlag New York, Inc.; 1994.

50. Cooper DM, Dietz FR. Treatment of idiopathic clubfoot. A thirty-year follow-up note. J Bone Joint Surg Am 1995;77:1477-89.

51. Ponseti IV. Congenital Clubfoot, fundamentals of treatment. second edition ed. Oxford: University Press; 2008.

52. Simons GW. Complete subtalar release in club feet. Part I--A preliminary report. J Bone Joint Surg Am 1985;67:1044-55.

53. Simons GW. Complete subtalar release in club feet. Part II--Comparison with less extensive procedures. J Bone Joint Surg Am 1985;67:1056-65.

54. Simons GW. The complete subtalar release in clubfeet. Orthop Clin North Am 1987;18:667-88.

55. McKay DW. New concept of and approach to clubfoot treatment: section I-principles and morbid anatomy. J Pediatr Orthop 1982;2:347-56.

56. McKay DW. New concept of and approach to clubfoot treatment: section II--correction of the clubfoot. J Pediatr Orthop 1983;3:10-21.

57. McKay DW. New concept of and approach to clubfoot treatment: Section III--evaluation and results. J Pediatr Orthop 1983;3:141-8.

58. Wang ZG, Cai HQ, Chen BC, et al. Ponseti treatment of congenital clubfoot. Chinese Journal of Pediatric Surgery 2004;25:54-6.

59. Lin G, Tang K, Lou Y, et al. Therapeutic Effect of Ponseti Method Treatment on Congenital Clubfoot. Journal of Applied Clinical Pediatrics 2007;22:1753-4.

60. Wang ZG, Cai HQ, Chen BC, et al. Importance of percutaneous tendoachilles tenotomy in Ponseti method. Orthopedic Journal of China 2007;15:817-20.

61. Xu M, Liu CL, Yang X. Ponseti Method for Treatment of Congenital clubfoot. Journal of Clinical Pediatric Surgery 2007;6:65-6.

62. Yao MY, Zhang F, Hou GJ, et al. Ponseti technique in the treatment of congenital clubfoot in children. Henan Journal of Surgery 2007;13:22-3.

63. Editor. Summary of Panseti Therapy for Congenital Clubfoots. Orthopedic Journal of China 2008;16:799.

64. Ma RX, Zhang XX. Early conservative treatment of congenital clubfoot - principles and techniques of Bensahel methods. Chinese Journal of Pediatric Surgery 2008;29:122-3.
65. Zhao GP, Liu ZT, Tang JD, et al. Effect of Modified Ponseti Method on Congenital Clubfoot. Orthopedic Journal of China 2009;17:1670-2.

66. Jiao HJ, Hu X, Yuan JR, et al. Carroll surgery for congenital clubfoot. China Practical Medicine 2009;4:117-8.

67. Zhong T, Li M, Liu CK, et al. CarrolI procedure for the treatment of congenital clubfoot. Chinese Journal of Pediatric Surgery 2009;30:703-6.

68. Zhao AQ, Bai R. Ponseti approach in the treatment of recurrent or severe congenital horseshoe pronation. Journal of Inner Mongolia Medical University 2020;42:436-8+43.

69. Zha GS. A report of four cases of congenital clubfoot treated by manipulation and fixed plate. Chinese Manipulation \& Qigong Therapy 1990;32:44+7.

70. Ma C, Wang XL, Huang J, et al. Manipulation and orthopaedic foot support for congenital equinovarus. Foreign Medical Sciences(Physical Medical and Rehabilitation) 2005;25:134.

71. Chen FX. Manipulation correction of 30 cases of congenital clubfoot in children. China Practical Medicine 2010;5:236-7.

72. Wang KZ, Yang JS, Zheng XM, et al. Clinical Effect of Manipulation Massage combined with Pansetti Method in the Treatment of Infantile Congenital clubfoot. Nei Mongol Journal of Traditional Chinese Medicine 2017;36:120.

73. Zheng YY, Huang JF. To explore the early screening massage in auxiliary Ponseti technology treatment the effect of CCF. Jilin Medical Journal 2014;35:5824-5.

74. Luo QJ. Acupuncture and moxibustion knife treating stiff congenital equinovarus. The Journal of Traditional Chinese Orthopedics and Traumatology 2000;12:26.

75. Zheng GM, Yao SH. A report of 30 cases of congenital equinovarus treated with integrated Chinese and western medicine. Jiangsu Journal of Traditional Chinese Medicine 1991;23:23-5.

76. Yan YJ, Yan YW, Yan YL, et al. Treatment of 186 Cases of Congenital Horseshoe with Integrated Chinese and Western Medicine. China Journal of Orthopaedics and Traumatology 2000;13:44.

77. Lv FM, Wang L, Ai KBE. Treatment of congenital horseshoe varus in early childhood with integrated Chinese and western medicine. Xinjiang Journal of Traditional Chinese Medicine 2010;28:27-9.

78. Dobbs MB, Gurnett CA. The 2017 ABJS Nicolas Andry Award: Advancing Personalized Medicine for Clubfoot Through Translational Research. Clin Orthop Relat Res 
2017;475:1716-25.

79. Su Y, Xie Y, Kang X, et al. A polyaxial fixation brace for the treatment of idiopathic congenital talipes equinovarus in newborns. J Orthop Surg Res 2019;14:211.

80. Hui C, Joughin E, Nettel-Aguirre A, et al. Comparison of cast materials for the treatment of congenital idiopathic clubfoot using the Ponseti method: a prospective randomized controlled trial. Can J Surg 2014;57:247-53.

81. Wang ZG, Cai HQ, Zhang YC, et al. Relapsing clubfoot with Ponseti method cause and treatment. Chinese Journal of Pediatric Surgery 2009;30:543-6.

82. Zhou QH, Zhong SF, Liu YZ. Evaluation of the operation of congenital clubfoot and analysis of the causes of recurrence. Guangdong Medical Journal 2007;28:1970-1.

83. Qi JF, Wu RY. Effect of Family-centered Care on Postoperative Nursing and Parental Satisfaction of clubfoot Plaster. Journal of Qilu Nursing 2018;24:40-2.

84. Ding F, Shen Y, Yan LX. Effect of 'family participation' nursing mode on foot function and sleep quality of congenital clubfoot. World Journal of Sleep Medicine 2018;5:468-71.

85. Li B, Zhang W, Liu ZJ. Application of WeChat Platform in Health Education of Children with Congenital Clubfoot by Ponseti Methods. Journal of China Medical University 2017;46:78-81.

86. Ai AB, Chen GJ, Wang JJ, et al. Association between FOX01 gene congenital talipes equinovarus polymorphisms and idiopathic of Uighur from Xinjiang China Journal of Modern Medicine 2016;26:54-8.

Cite this article as: $\mathrm{Li} \mathrm{J,} \mathrm{Li} \mathrm{Y,} \mathrm{Xu} \mathrm{H,} \mathrm{Canavese} \mathrm{F.} \mathrm{Clubfoot}$ treatment in China before and after the advent of the Ponseti technique: a historical narrative review. Ann Transl Med 2021;9(13):1107. doi: 10.21037/atm-20-8042
87. Chen GJ, Ai AB, Wang JJ, et al. Association between idiopathic congenital talipes equinovarus and gene family. China Journal of Modern Medicine 2016;26:14-7.

88. Chen GJ, Lv FM, Wang JJ, et al. Pathogenic relation between GLI3 expression and idiopathic congenital talipes equinovarus in Xinjiang Uygur nationality. Shandong Medical Journal 2016;56:21-3.

89. Chen XY, Zhang JW, Shi XY. Mutations of HOXD13 Gene and Its Related Diseases. Journal of Shenyang Medical College 2017;19:371-4.

90. Jiang YS, Zhang XG. Loeys-Dietz syndrome caused by mutation in TGFBR2 gene: a case report. Journal of Clinical Pediatrics 2019;37:538-40.

91. Lu GM, Li SH, Zhou MW, et al. Research advances in pathogenic genes and hereditary factors of congenital talipes equinovarus. Journal of Clinical Pediatric Surgery 2020;19:789-93.

92. Li J, Wu J, Liu Y, et al. HOXA9 rs3801776 G>A polymorphism increases congenital talipes equinovarus risk in a Chinese population. J Gene Med 2019;21:e3119.

93. Dobbs MB, Gurnett CA. Genetics of clubfoot. J Pediatr Orthop B 2012;21:7-9.

94. Zhang TX, Haller G, Lin P, et al. Genome-wide association study identifies new disease loci for isolated clubfoot. J Med Genet 2014;51:334-9.

95. Weymouth KS, Blanton SH, Bamshad MJ, et al. Variants in genes that encode muscle contractile proteins influence risk for isolated clubfoot. Am J Med Genet A 2011;155A:2170-9. 